\title{
Research on the History of Publishing in China 中国出版史研究
}

Contents of fourth issue, 2016

Chen Wanxiong, 'Before and after "1997": history and the status quo of the H K publishing industry'

Li Jiaju, 'Reviewing the past and envisioning the future: the history of the textbook publishing industry in Hong Kong'

Chow Kai Wing, 'The Commercial Press in wartime China: a case study of the Hong Kong branch'

Chen Shurong, 'A brief history of the printing and publishing industry in Macao'

$\mathrm{Wu}$ Yonggui and Zhu Lin, 'A review of the compilation of historical materials on China's publishing industry since 2010'

Li Jingduan, 'The evolution of the internal circulation system'

Jiang Shaoli, 'On book review magazines: Reading monthly magazine and Reading semimonthly magazine in the 1950s'

Yang Hua, 'Choushi jinnang, a popular ritual encyclopedia'

Wu Shideng, 'The operation and features of the Sibao Bookstore'

Wu Dexiang, 'A study of the woodblock printing techniques that originated in Sibao Village'

Zhang Xiaoli, 'A study of the Imperial Palace Printing House'

Yang Dongfang and Zhou Mingjian, 'The publication of traditional Chinese medicine in the period of the Republic of China'

Dong Xingjie, 'A study of the publication and distribution of the 1985 version of Jingpingmei cihua' 